\title{
Bipolar and unipolar schemes for confined band variable switching frequency PWM based inverter
}

\author{
Hussain Attia ${ }^{1}$, Hang Seng Che ${ }^{2}$, Tan Kheng Suan Freddy ${ }^{3}$, Ahmad Elkhateb ${ }^{4}$ \\ ${ }^{1}$ Electrical, Electronics and Communication Engineering Dept., American University of Ras Al Khaimah, UAE \\ ${ }^{2}$ UM Power Energy Dedicated Advanced Centre, University of Malaya, Kuala Lumpur, Malaysia \\ ${ }^{3}$ School of Engineering, Asia Pacific University of Technology and Innovation, Kuala Lumpur, Malaysia \\ ${ }^{4}$ School of Electronics, Electrical Engineering and Computer Science, Queen's University, Belfast, NI, UK
}

\begin{tabular}{l}
\hline \hline Article Info \\
\hline Article history: \\
Received Jun 29, 2020 \\
Revised Oct 9, 2020 \\
Accepted Jan 11, 2021
\end{tabular}

Keywords:

Bipolar scheme

Confined band variable

switching frequency pulse

width modulation

Harmonics spectrum

MATLAB/Simulink

Single-phase inverter

Total harmonic distortion

Unipolar scheme

\begin{abstract}
The single phase inverter performance through the unipolar and bipolar strategies has been previously analyzed based on the constant switching frequency pulse width modulation (CSFPWM). However, the confined band variable switching frequency PWM (CB-VSFPWM) is currently proposed as a new variable switching frequency PWM technique through unipolar strategy to facilitate the design of high order filter, to reduce the switching losses, and to reduce the current total harmonics distortion (THD) as well. To evaluate the performance of a single phase inverter based on the CBVSFPWM through bipolar strategy, this paper presents a comparative study of the CB-VSFPWM based inverter performance using the unipolar PWM and the bipolar PWM strategies. The study adopts MATLAB/Simulink to simulate the inverter and to analyze the simulation results in terms of harmonics spectrum, total harmonic distortion (THD), and fundamental components. The analysis of the study results gives an indication about the appropriate type of CB-VSFPWM strategy (unipolar PWM or bipolar PWM) to guarantee the desired performance of the connected inverter in terms of the electrical grid standards like THD, and harmonics spectrum of the inverter current.
\end{abstract}

This is an open access article under the CC BY-SA license.

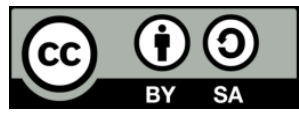

\section{Corresponding Author:}

Hussain Attia

Department of Electrical, Electronics and Communication Engineering

American University of Ras Al Khaimah

Ras Al Khaimah, 10021, UAE

Email: hattia@aurak.ac.ae

\section{INTRODUCTION}

Single phase inverter has been played a major role in converting stage of a direct current DC renewable energy source to an alternating current AC electricity either to be delivered to the AC loads in a standalone system or to be supplied to a utility grid through a grid connected system [1]-[3]. The power conversion systems of high performance inverters are characterized by high efficiency due to the reduction in the switching and conduction losses, and the enhancement in the total harmonic distortion (THD) level [4]-[6].

The harmonics spectrum of the inverter current is affected by the drive pulses generation scheme. Pulse width modulation (PWM) technique is a suitable one to have low harmonic levels and low THD through using constant carrier switching frequency during the fundamental frequency cycle [7]-[11]. In addition to controlling the switching losses through a simple pulses generation process in both standalone and grid connected systems. Reducing switching losses represents improving the inverter efficiency [12], [13]. In 
constant switching frequency pulse width modulation (CSFPWM), the inverter switches are driving through the pulse width modulation method of pulses generation using one of the two PWM schemes; unipolar scheme and bipolar scheme. However, the disadvantage of the PWM technique is that the difficulty in guaranteeing a low THD and low switching losses simulitanuosly. In other words, to have low THD, switching frequency should be increased that will reduce the filter size as well. But increasing the switching frequency increases the switching losses, this reduces the inverter efficiency. Whereas to improve the efficiency, switching losses should be reduced by reducing the switching frequency, but this will increase the current THD [14]-[16]. To manipulate the mentioned demerit of the constant switching frequency PWM technique for inverter drive pulses generation, the researchers have proposed the variable switching frequency pulse width modulation CSFPWM for enhancing the THD, switching losses, and more flexible pulses generating as well [17]-[28].

In the studies of [17]-[19], random variable switching frequency pulse width modulation (R-VSFPWM) have proposed for distributing the harmonics over a wide frequency band through adopting a random carrier frequency variation during the fundamental frequency cycle. This technique is proposed to have effectively suppressing the electromagnetic interference (EMI) noise in the power electronics conversion system. Another type of variable switching frequency PWM technique is optimal VSFPWM which have proposed to guarantee the minimum switching losses and the desired THD level in the output current of the inverter.

Recently, a new type of VSFPWM technique which is the confined band VSFPWM (CB-VSFPWM) has proposed in [24], and [25] for single phase inverters. The CB-VSFPWM technique has proposed and analyzed through unipolar scheme. This technique facilitated the low pass power filter design and avoided the restrict of the practical applications due to that the process of unconfined band of the switching frequency variation had led to the possibility of a filter resonating, and distortion possibility of the load current due to the pulse dropping by exceeding the maximum switching frequency limit [26]-[28].

Based on the above, this paper discusses and analyzes the effects of the bipolar PWM strategy on the performance of a CB-VSFPWM inverter through a comparative study between the unipolar and bipolar PWM schemes. The remaining sections of the paper are as follows: the methodology of the unipolar and bipolar PWM schemes are explained in section 2. In section 3, the principle of the CB-VSFPWM is explained. The analysis of the simulation results of the inverter voltage and current waveforms for the two schemes through the CB-VSFPWM are shown in section 4. Conclusion of the study outcomes is discussed in section 5 .

\section{BIPOLAR AND UNIPOLAR PULSE WIDTH MODULATION PWM SCHEMES}

Pulse width modulation technique is a common technique to generate the driving pulses for the inverter system due to the simplicity in controlling the inverter voltage by controlling the duty cycle of the drive pulses. PWM based power electronics circuits and systems have many home and industrial applications, such as; motor speed controller, inverter/converter systems, and many more. The PWM inverters have many merits such as easy controlling the inverter output voltage, reducing the level of inverter current harmonics, and simple controlling function [29]-[33]. A major type of PWM is sinusoidal PWM (SPWM) which drive pulses can be obtained by one of the two strategies; unipolar and bipolar [34].

\subsection{Bipolar SPWM}

The process of implementing the bipolar sinusoidal PWM pulses generation for a single phase full bridge inverter is explained in Figure 1. A sinusoidal signal of reference fundamental frequency is compared with a triangular signal of carrier frequency. The value and the sign of the output voltage depend on the instantaneous values of reference and carrier waveforms. The output voltage will be $+\mathrm{Vdc}$ or $-\mathrm{Vdc}$ depending on the instantaneous values of the comparison levels of the reference and carrier signals as shown in (1):

$$
\begin{aligned}
& v_{o}=+V_{d c} \text { when } v_{\text {sine }}>v_{\text {tri }} \\
& v_{o}=-V_{d c} \text { when } v_{\text {sine }}<v_{\text {tri }}
\end{aligned}
$$

To have $v_{o}$ is equal to $+\mathrm{V}_{\mathrm{dc}}, \mathrm{Q}_{1}$, and $\mathrm{Q}_{2}$ are on, whereas to have $v_{o}$ is equal to $-\mathrm{V}_{\mathrm{dc}}, \mathrm{Q}_{3}$, and $\mathrm{Q}_{4}$ are on. It is noticeable in bipolar scheme that the switching frequency of output signal is the same as the carrier frequency signal. 


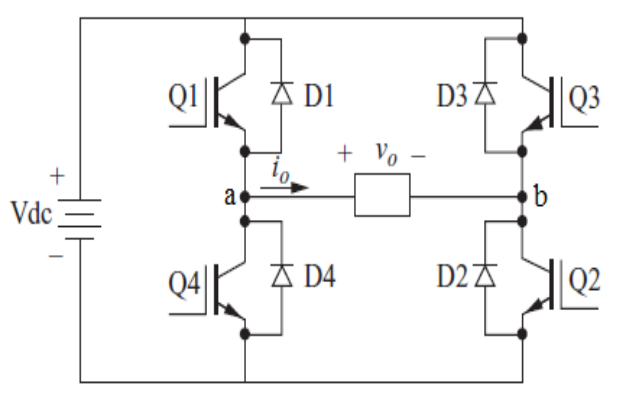

(a)

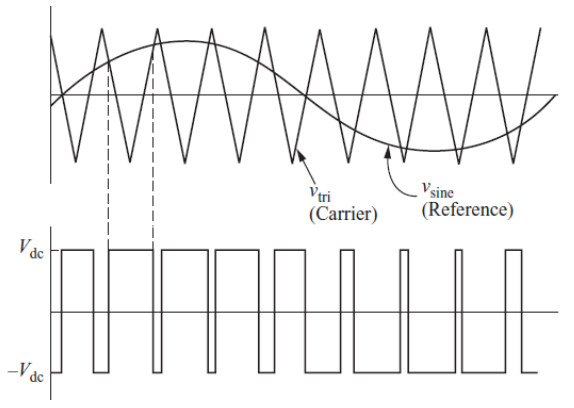

(b)

Figure 1. Single phase inverter with sinusoidal PWM scheme; (a) Full bridge inverter, (b) Bipolar PWM scheme [34]

\subsection{Unipolar SPWM}

Figure 2 shows the process of implementing the unipolar sinusoidal PWM scheme for a full bridge single phase inverter. To have a unipolar sinusoidal PWM scheme, the output is switched among three levels: $+\mathrm{V}_{\mathrm{dc}}$, zero voltage, or $-\mathrm{V}_{\mathrm{dc}}$. In unipolar scheme, the output voltage also depending on the instantaneous values of the the reference and carrier signals, the switch controls are as:

$$
\begin{aligned}
& \mathrm{Q}_{1} \text { is on when } v_{\text {sine }}>v_{t r i} \\
& \mathrm{Q}_{2} \text { is on when }-v_{\text {sine }}<v_{t r i} \\
& \mathrm{Q}_{3} \text { is on when }-v_{\text {sine }}>v_{t r i} \\
& \mathrm{Q}_{4} \text { is on when } v_{\text {sine }}<v_{t r i}
\end{aligned}
$$

In unipolar scheme, the switch pairs $\left(\mathrm{Q}_{1}, \mathrm{Q}_{4}\right)$ and $\left(\mathrm{Q}_{2}, \mathrm{Q}_{3}\right)$ are complementary, and output voltage alternates between $+V_{d c}$ and zero, or between $-V_{d c}$ and zero. It is noticeable in unipolar scheme that the switching frequency of output signal is a twice of the carrier frequency signal.
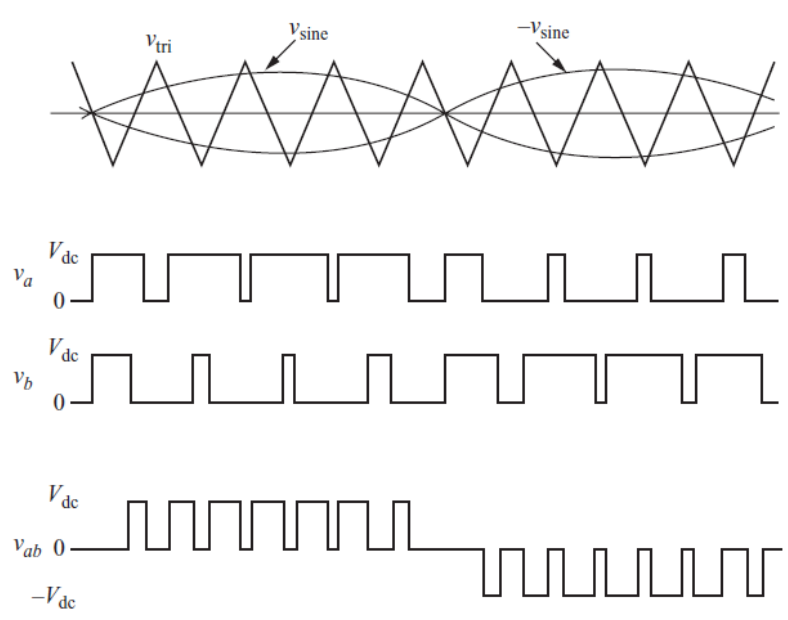

Figure 2. Single phase full bridge inverter with unipolar sinusoidal PWM scheme [34]

\section{CONFINED BAND VSFPWM WITH BIPOLAR AND UNIPOLAR SCHEMES}

A new VSF PWM is proposed in [24], and [25] which is the confined band VSFPWM (CBVSFPWM). The CB-VSFPWM is confining the frequency spectrum within a desired frequency band between a minimum switching frequency $f_{\min }$ and a maximum switching frequency $f_{\max }$ which equals to the carrier frequency $f_{c}$ of CSFPWM technique as shown in (2), and (3):

$$
f_{\max }=f_{c}
$$

$$
f_{\min }=B \cdot f_{c} \quad B \in[0,1]
$$


where $B$ is a frequency control parameter, when $\mathrm{B}=1$, the CB-VSFPWM scheme becomes CSFPWM. In study [24], CB-VSFPWM technique is proposed to have many merits in terms of current harmonics spectrum, total harmonic distortion THD, filter design, and inverter efficiency. The CB-VSFPWM technique is varying the switching frequency with respect to the reference frequency cycle as explained in (4):

$$
f_{C B-V S F}=f_{C} \cdot\{1-[(1-B) \cdot \operatorname{abs}(\sin (\omega t))]\}
$$

The behavior of (4) is shown in Figure 3, the variable switching frequency $f_{C B \text {-VSF }}$ is starting with maximum frequency level at the minimum voltage amplitude and reaching the minimum level at the maximum voltage amplitude. The confined switching frequency range can be selected within a variable frequency band which is $B \cdot f_{C}<f_{C B-V S F}<f_{C}$, and this indicates the importance of the parameter $B$ of the proposed CB-VSFPWM. Figure 4 shows the behavior of the CB-VSFPWM in bipolar and unipolar schemes.

Comparing with the CSFPWM technique, the CB-VFSPWM technique is working on reducing the number PWM pulses within one fundamental cycle at minimizing B. This definitely reduces the switching losses and low order harmonic. According to (4), when $\mathrm{B}=1.0, f_{C B-V S F}=f_{C}$, and the switching scheme will be similar to the constant switching frequency.

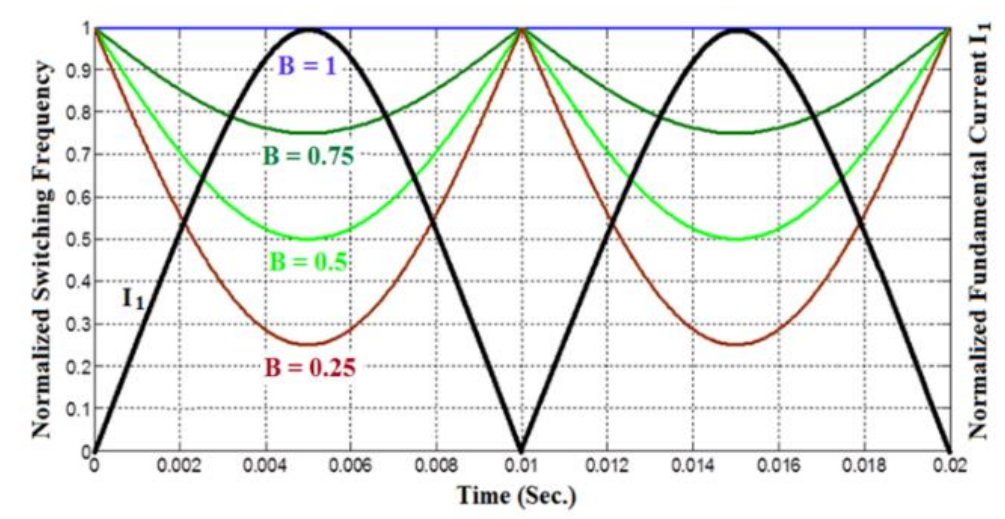

Figure 3. Behavior of the CB-VSFPWM technique for different values of B parameter [24]

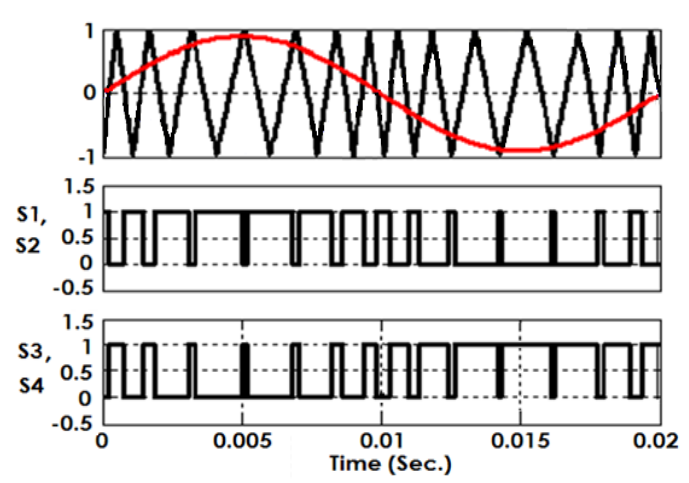

(a)

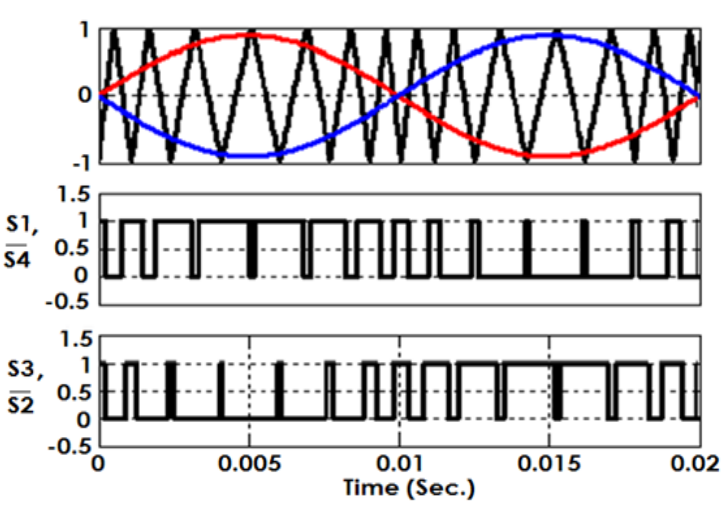

(b)

Figure 4. Drive pulses generation for a CB-VSFPWM based single phase full bridge inverter; (a) Bipolar CB-VSFPWM scheme, (b) Unipolar CB-VSFPWM scheme

\section{SIMULATION RESULTS ANALYSIS}

MATLAB/Simulink is adopted to implement the single phase full bridge inverter with the two PWM schemes bipolar and unipolar based on the CB-VFSPWM technique. The inverter parameters are shown in Table 1 for the two PWM schemes. A constant series inductor of $10 \mathrm{mH}$ is connected between the implemented inverter and a resistive load of $100 \Omega$. Figure 5 shows the Simulink simulation of the inverter 
system based on the CB-VSFPWM for the two schemes unipolar and bipolar. Based on the fact of that the effective switching frequency is the same as carrier frequency in the bipolar scheme inverter and double of the carrier frequency in the unipolar PWM scheme inverter.

Table 1. Inverter parameters

\begin{tabular}{lc}
\hline \multicolumn{1}{c}{ Parameter Name } & Parameter Value \\
\hline Input dc link voltage, $\mathrm{V}_{\mathrm{dc}}$ & $400 \mathrm{~V}$ \\
Rated Power & $0.75 \mathrm{~kW}$ \\
Constant carrier frequency, $f_{C}$ & $10 \mathrm{kHz}$ \\
CB-VSF carrier frequency range, $f_{C B-V S F}$ & $5 \mathrm{kHz}$ to $10 \mathrm{kHz}(B=0.5)$ \\
DC-link capacitor & $2200 \mu \mathrm{F}, 400 \mathrm{~V}$ \\
Load resistor & $100 \Omega$ \\
Modulation Index, $\mathrm{m}$ & 0.95 \\
L-filter & $10 \mathrm{mH}$ \\
\hline
\end{tabular}

(a)

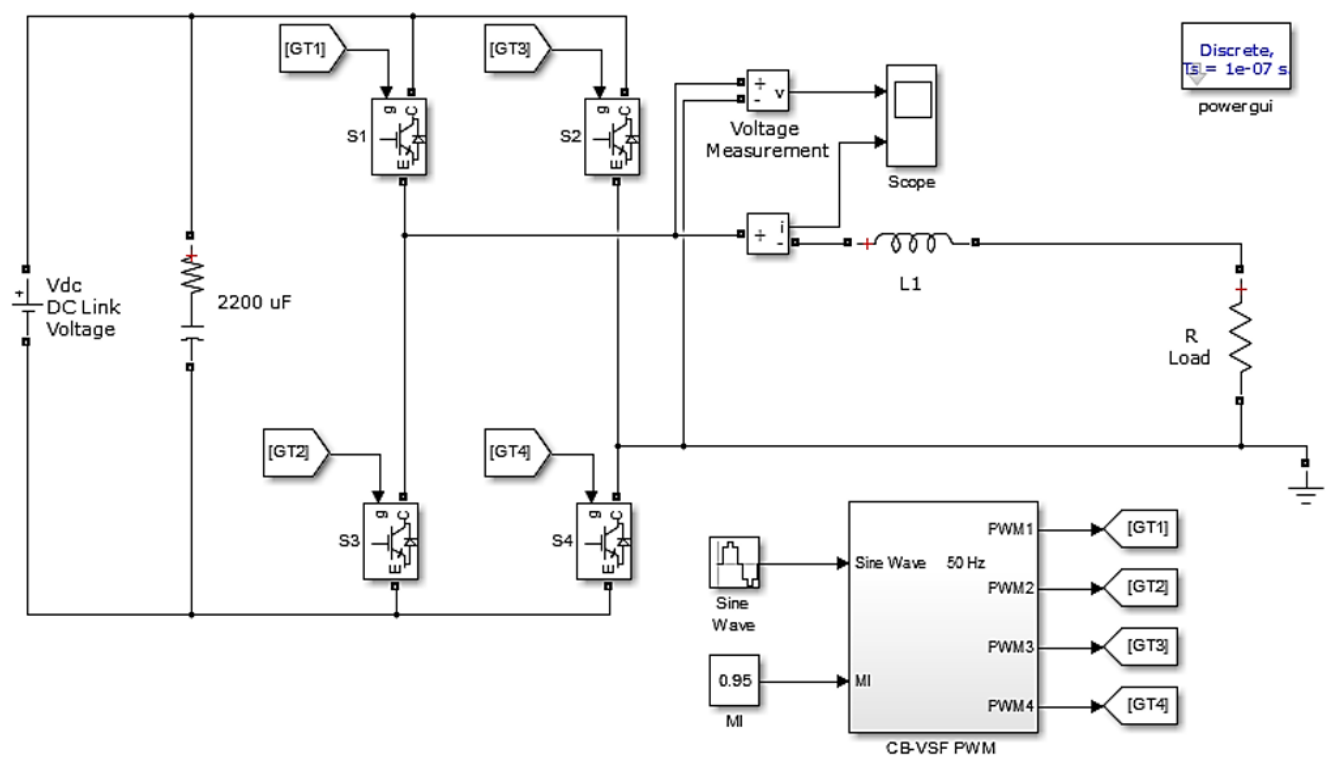

(b)

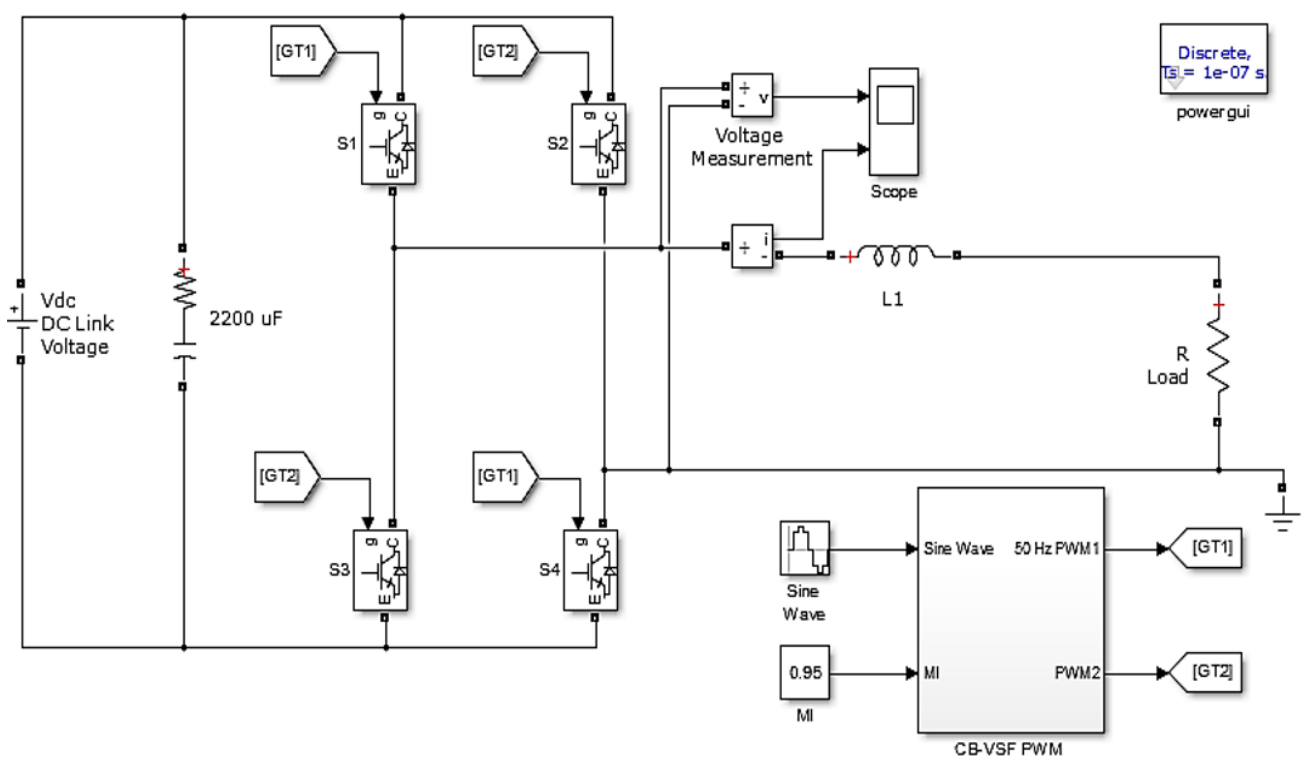

Figure 5. The simulated single phase full bridge inverter; (a) Unipolar CB-VSFPWM scheme,

(b) Bipolar CB-VSFPWM scheme

Figure 6 shows the inverter output voltage and current with the harmonics spectrum and THD level as well. Figure 6 shows the two levels $(400 \mathrm{~V}$, and $-400 \mathrm{~V})$ of the inverter output voltage, and the harmonics 
spectrum variation during the carrier frequency variation of ( $5 \mathrm{kHz}$ to $10 \mathrm{kHz}$, and above) with high level of THD (103.37\%). Figure 6 also shows the inverter current waveform after the effect of the series L-filter, the harmonics spectrum is shown in a frequency band starting from $5 \mathrm{kHz}$ to the $10 \mathrm{kHz}$ and above. THD level is $(21.84 \%)$ which represents an unaccepted level by considering the grid standards [35].
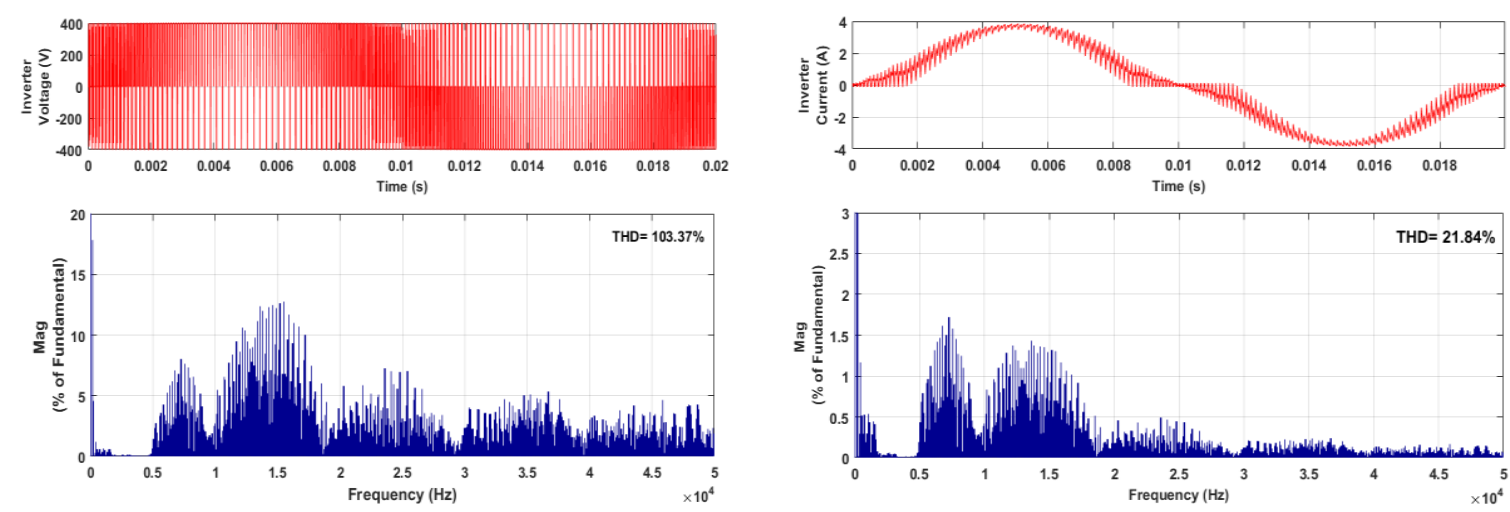

(a)

(b)

Figure 6. Bipolar CB-VSFPWM based inverter, (a) Output voltage with the harmonics spectrum and THD level, (b) Output current with the harmonics spectrum and THD level

Figure 7 shows the inverter performance based on the unipolar CB-VSFPWM, the three levels $(400 \mathrm{~V}, 0 \mathrm{~V}$, and $-400 \mathrm{~V})$ of the inverter voltage, and the harmonics spectrum variation are noted at the effective switching frequency $(10 \mathrm{kHz}$ to $20 \mathrm{kHz})$, which is the double of the carrier frequency variation ( $5 \mathrm{kHz}$ to $10 \mathrm{kHz}$, and above). Lower level of THD (52.36\%) of inverter current is recorded. Figure 7 shows also the inverter current waveform through using the series L-filter based on unipolar CB-VSFPWM. The harmonics spectrum is appeared within a frequency band starting from $10 \mathrm{kHz}$ to the $20 \mathrm{kHz}$ and above. THD level $(5.24 \%)$ is monitored which is very close to the accepted limit of the grid standard. In other words, it will be definitely accepted if a high order power filter [25] is inserted instead of the L-filter.
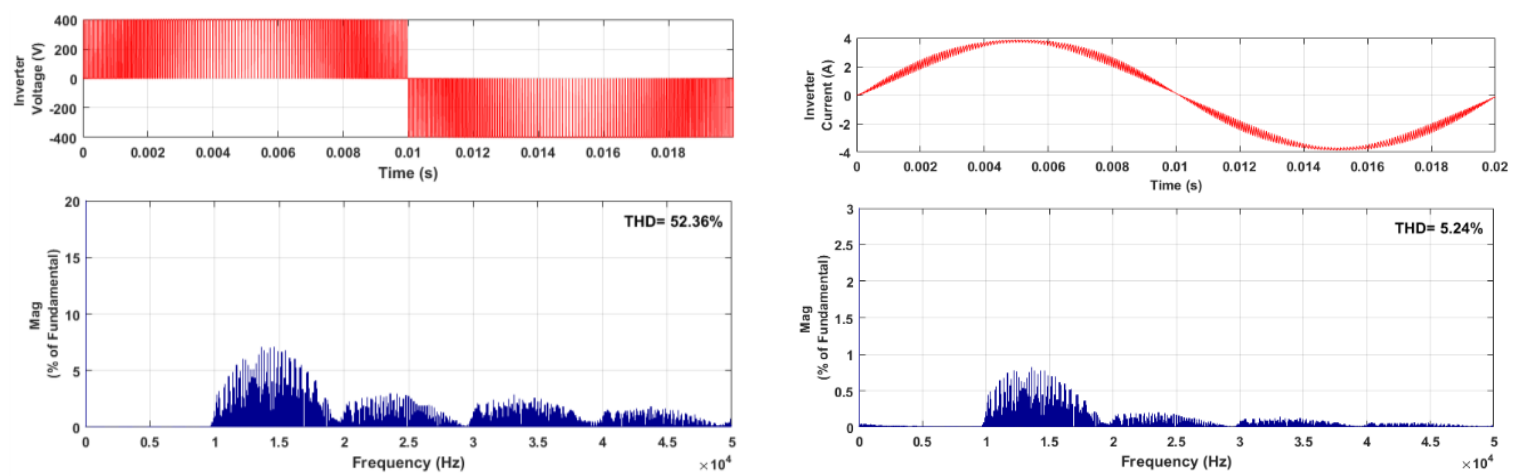

(a)

(b)

Figure 7. Unipolar CB-VSFPWM based inverter; (a) Output voltage with the harmonics spectrum and THD level, (b) Output current with the harmonics spectrum and THD level

Figure 8 proves the priority of the unipolar CB-VSFPWM on the bipolar CB-VSFPWM after investigating the harmonics spectrum with the THD level of inverter output voltage (THD=98.03\%) and current (THD=21.79\%) show the effect of adopting higher carrier frequency variation using the bipolar scheme. Figure 8 shows higher harmonics and THD levels using a higher range of carrier frequency using the bipolar scheme, comparing with the counterparts of the unipolar scheme at the same frequency band. Figure 9 summarizes the THD levels comparisons, and clearly demonstrates the priority of Unipolar CB VSF PWM scheme. 

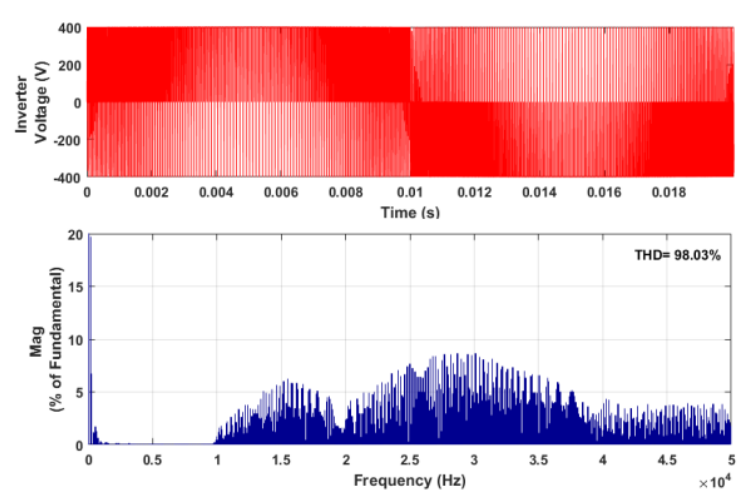

(a)
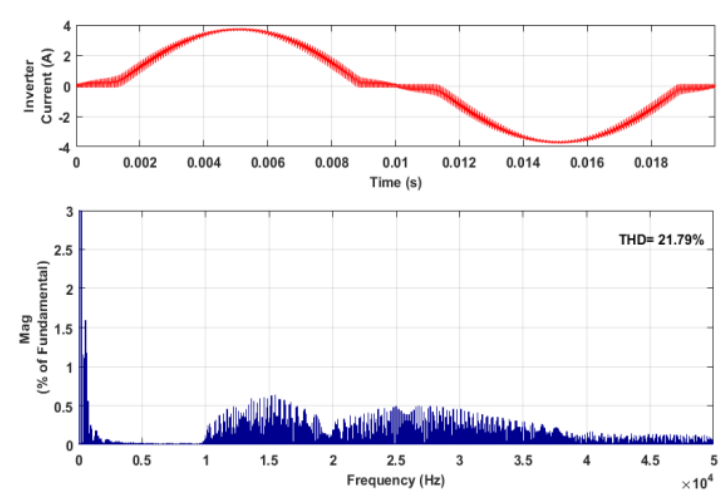

(b)

Figure 8. Bipolar CB-VSFPWM based inverter of $10 \mathrm{kHz}$ to $20 \mathrm{kHz}$ carrier frequency variation; (a) Output voltage with the harmonics spectrum and THD level, (b) Output current with the harmonics spectrum and THD level

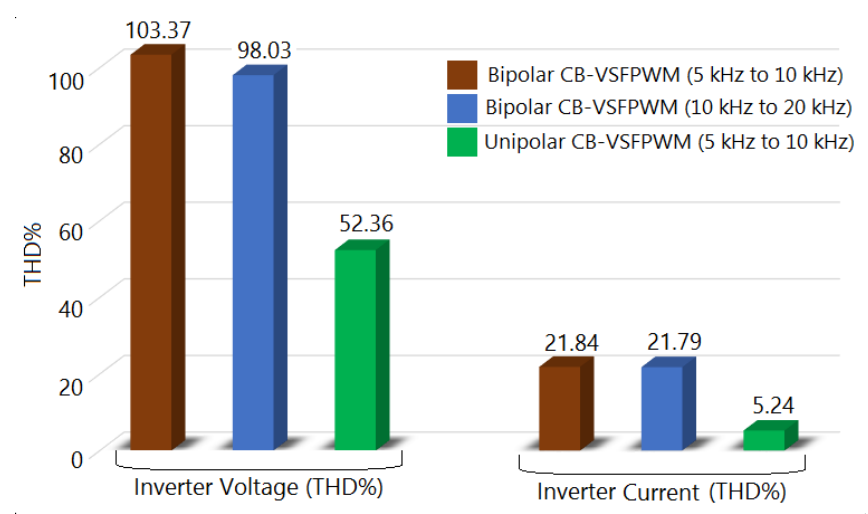

Figure 9. THD\% comparison between unipolar and bipolar schemes using the CB-VSFPWM technique

\section{CONCLUSION}

This paper presented a comparative study about the performance of a single phase full bridge inverter based on CB-VSFPWM technique, to evaluate the inverter performance based on the CB-VSFPWM using the bipolar drive pulses generation scheme. The study simulated and analyzed the inverter performance in terms of the voltage and current harmonics and THD levels for the two schemes; bipolar PWM and unipolar PWM. The study adopted the MATLAB/Simulink to simulate the $0.75 \mathrm{~kW}$ inverter system with a certain parameters settings. The study concluded that the levels of harmonics and total harmonic distortion THD are low using the unipolar scheme than the bipolar scheme, and this reflected positively on satisfying the grid standards. Even through considering the same switching frequency variation range, the unipolar CB-VSFPWM scheme offered lower harmonics and lower THD level compared to the bipolar CB-VSFPWM scheme.

\section{ACKNOWLEDGEMENTS}

The authors appreciate the financial support provided by school of engineering, American University of Ras Al Khaimah-UAE, www.aurak.ac.ae/en/school-of-engineering/.

\section{REFERENCES}

[1] Y. Yang, F. Blaabjerg, S. Waffler, and H. Wang, "Low-Voltage Ride-Through of Single-Phase Transformerless Photovoltaic Inverters," IEEE Trans. Ind. Appl., vol. 50, no. 3, pp. 1942-1952, Jun. 2014.

[2] F. T. K. Suan, N. A. Rahim, and H. W. Ping, "Three-phase transformerless grid-connected photovoltaic inverter to reduce leakage currents," in Proc. IEEE CEAT, Nov. 2013, pp. 277-280.

[3] V. S. Bharath and G. Mani, "Closed Loop Analysis of Multilevel Inverter Fed Drives," International Journal of Power Electronics and Drive System (IJPEDS), vol. 4, no. 3, pp. 337-342, Sep. 2014. 
[4] H. Attia, "Evaluation of Selective Harmonic Elimination Pulse Width Modulation Technique for Unipolar SinglePhase H-Bridge Inverter: Comparative Study," International Journal of Power Electronics and Drive Systems (IJPEDS), vol. 9, no. 3, pp. 1157-1165, 2018.

[5] H. Attia, M. Al Zarooni, and A. Cazan, "Ultrasonic Frequency Inverter for Piezoelectric Transducer Driving: The Negative Effects on Grid and the Intelligent Solution," 2019 International Conference on Electrical and Computing Technologies and Applications (ICECTA), Ras Al Khaimah, UAE, Nov. 2019.

[6] T. K. S. Freddy, N. A. Rahim, W. P. Hew, and H. S. Che, "Modulation techniques to reduce leakage current in three-phase transformerless H7 photovoltaic inverter," IEEE Trans. Ind. Electron., vol. 62, no. 1, pp. 322-331, 2015.

[7] Suresh N. and R. S. R. Babu, "Reduction of Total Harmonic Distortionin Cascaded H-Bridge Inverter by Pattern Search Technique," International Journal of Electrical and Computer Engineering (IJECE), vol. 7, no. 6, pp. 3292-3298, Dec. 2017.

[8] B. Sirisha and P. Satishkumar, "Simplified Space Vector Pulse Width Modulation based on Switching Schemes with Reduced Switching Frequency and Harmonics for Five Level Cascaded H-bridge Inverter," International Journal of Electrical and Computer Engineering (IJECE), vol. 8, no. 5, pp. 3417-3426, Oct. 2018.

[9] D. Chowdhury, M. S. Miah, Md. F. Hossain, and U. Sarker, "Implementation of a grid-tied emergency back-up powersupply for medium and low power applications," International Journal of Electrical and Computer Engineering (IJECE), vol. 10, no. 6, pp. 6233-6243, Dec. 2020.

[10] A. S. Al-Ogaili et al., "Time-domain harmonic extraction algorithms for three-level inverter-based shunt active power filter under steady-state and dynamic-state conditions-an evaluation study," International Journal of Electrical and Computer Engineering (IJECE), vol. 10, no. 6, pp. 5609-5620, Dec. 2020.

[11] D. T. Nugroho Suroso, and T. Noguchi, "New Dead-Time Compensation Method of Power Inverter Using Carrier Based Sinusoidal Pulse-Width Modulation," International Journal of Electrical and Computer Engineering (IJECE), vol. 8, no. 6, pp. 4880-4891, Dec. 2018.

[12] A. Bouknadel, N. Ikken, A. Haddou, N. E. Tariba, H. El Omari, and H. El Omari, "A new SOGI-PLL method based on fuzzy logic for grid connected PV inverter," International Journal of Electrical and Computer Engineering (IJECE), vol. 9, no. 4, pp. 2264-2273, Aug. 2019.

[13] B. Vasilev, "Analysis and improvement of the efficiencyof frequency converters with pulse width modulation," International Journal of Electrical and Computer Engineering (IJECE), vol. 9, no. 4, pp. 2314-2320, Aug. 2019.

[14] S. Vashishtha and K. R. Rekha, "A Survey: Space Vector PWM (SVPWM) in $3 \varphi$ Voltage Source," International Journal of Electrical and Computer Engineering (IJECE), vol. 8, no. 1, pp. 11-18, Feb. 2018.

[15] Suresh N. and R. S. R. Babu, "Reduction of Total Harmonic Distortion in Cascaded H-Bridge Inverter by Pattern Search Technique," International Journal of Electrical and Computer Engineering (IJECE), vol. 7, no. 6, pp. 3292-3298, Dec. 2017.

[16] M. J. Ghorbani and H. Mokhtari, "Impact of Harmonics on Power Quality and Losses in Power Distribution Systems," International Journal of Electrical and Computer Engineering (IJECE), vol. 5, no. 1, pp. 166-174, 2015.

[17] A. M. Trzynadlowski, K. Borisov, Y. Li, and L. Qin, "A novel random PWM technique with low computational overhead and constant sampling frequency for high-volume, low-cost applications," IEEE Trans. Power Electron., vol. 20, no. 1, pp. 116-122, Jan. 2005.

[18] B. Huo and A. M. Trzynadlowski, "Random Pulse Width PWM Modulator for Inverter-fed Induction Motor Based on the TMS320F240 DSP Controller," DSPS Fest '99, [Online]. Available: http://www.ti.com/sc/docs/general/dsp/fest99/poster/ahuotrzynad.pdf.

[19] S. M. Ali, V. V. K. Reddy, and M. S. Kalavathi, "Coupled random PWM technique for dual inverter fed induction motor drive," International Journal of Power Electronics and Drive Systems (IJPEDS), vol. 10, no. 1, pp. 58-65, Mar. 2019.

[20] A. Hussain, A. Yousif, and W. Hew, "Design and analysis for high performance synchronized inverter with PWM power control," in Proc. IEEE Clean Energy Technol., Nov. 2013, pp. 265-270.

[21] X. Mao, R. Ayyanar, and H. K. Krishnamurthy, "Optimal variable switching frequency scheme for reducing switching loss in single-phase inverters based on time-domain ripple analysis," IEEE Trans. Power Electron., vol. 24, no. 4, pp. 991-1001, Apr. 2009.

[22] D. Zhang, F.Wang, S. El-Barbari, J. Sabate, and D. Boroyevich, "Improved asymmetric space vector modulation for voltage source converters with low carrier ratio," IEEE Trans. Power Electron., vol. 27, no. 3, pp. 1130-1140, Mar. 2012.

[23] D. Jiang and F. Wang, "Variable switching frequency PWM for three-phase converters based on current ripple prediction," IEEE Trans. Power Electron., vol. 28, no. 11, pp. 4951-4961, Nov. 2013.

[24] H. A. Attia, T. K. S. Freddy, H. S. Che, W. P. Hew, and A. H. El Khateb, "Confined Band Variable Switching Frequency Pulse Width Modulation (CB-VSF PWM) for a Single-Phase Inverter With an LCL Filter," IEEE Transactions on Power Electronics, vol. 32, no. 11, pp. 8593-8605, 2017.

[25] H. A. Attia, T. K. S. Freddy, H. S. Che, and A. H. El Khateb, "Design of LLCL Filter for Single Phase Inverter with Confined Band Variable Switching Frequency (CB-VSF) PWM," Journal of Power Electronics, vol. 19, no. 1, pp. 44-57, Jan. 2019.

[26] S. Parker, B. McGrath, and D. G. Holmes, "Regions of active damping control for LCL filters," IEEE Trans. Power Electron., vol. 50, no. 1, pp. 424-432, Jan. 2014.

[27] M. Liserre, F. Blaabjerg, and S. Hansen, "Design and control of an LCL filter-based three-phase active rectifier," IEEE Trans. Ind. Appl., vol. 41, no. 5, pp. 1281-1291, Sep-Oct. 2005. 
[28] M. Huang, X. Wang, P. C. Loh, and F. Blaabjerg, "LLCL-Filtered Grid Converter with improved stability and robustness," IEEE Trans. Power Electron., vol. 31, no. 5, pp. 3958-3967, May 2016.

[29] J. Soomro, T. D. Memon, and M. A. Shah, "Design and Analysis of Single Phase Voltage Source Inverter Using Unipolar and Bipolar Pulse Width Modulation Techniques," 2016 International Conference on Advances in Electrical, Electronic and System Engineering, Putrajaya, Malaysia, Nov. 2016.

[30] P. N. Enjeti, P. D. Ziogas, and J. F. Lindsay, "Programmed PWM techniques to eliminate harmonics: A critical evaluation," IEEE transactions on Industry Applications, vol. 26, pp. 302-316, Apr. 1990.

[31] B. P. Reddy, K. S. Reddy, and B. S. S. Reddy, "Novel Single Phase Full Bridge Inverter Formed by Floating Capacitors," International Journal of Power Electronics and Drive Systems (IJPEDS), vol. 7, no. 1, pp. 193-201, Mar. 2016.

[32] K. H. Law, W. P. Q. Ng, and W. K. Wong, "Flyback Cascaded Multilevel Inverter Based SHE-PWM Control for STATCOM Applications," International Journal of Power Electronics and Drive Systems (IJPEDS), vol. 8, no. 1, pp. 100-108, Mar. 2017.

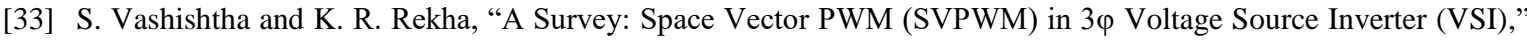
International Journal of Electrical and Computer Engineering (IJECE), vol. 8, no. 1, pp. 11-18, Feb. 2018.

[34] D. W. Hart, "Power Electronics," Published by McGraw-Hill, New York, NY 10020, 2011.

[35] IEEE Recommended Practices and Requirements for Harmonic Control in Electric Power Systems, IEEE Std. 5191992, 1992.

\section{BIOGRAPHIES OF AUTHORS}
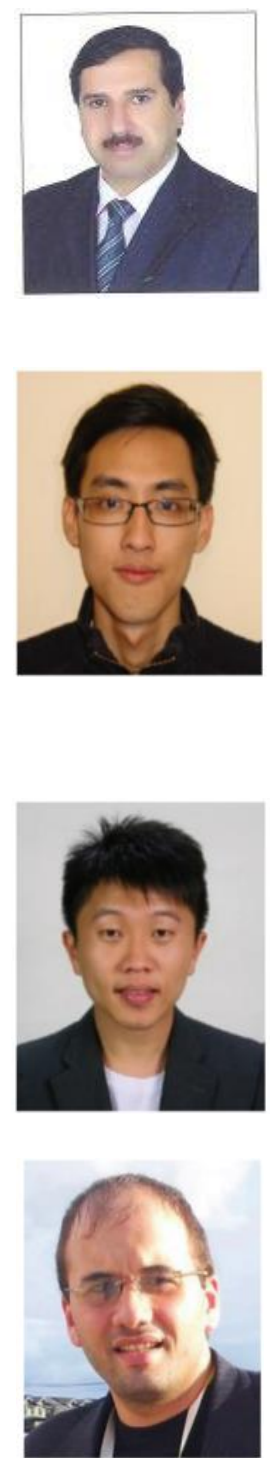

Hussain Attia earned his Ph.D. degree in power electronics from University of Malaya, Kuala Lumpur, Malaysia, and M.Sc. degree in electronic engineering from the University of Technology, Baghdad, Iraq. Currently, He is working as a faculty member in Department of Electrical, Electronics and Communications Engineering at American University of Ras Al Khaimah, Ras Al Khasimah, UAE. He served as a technical and organizing member for many IEEE and international conferences such as ICEDSA / 2016, ICECTA / 2017, ICEWES / 2018, and ICECTA / 2019. Hussain's research interests include power electronics, AC \& DC Drives, PWM Inverters (single phase \& three phases), harmonics reduction techniques, and intelligent control.

Hang Seng Che received his B.Eng. degree in Electrical Engineering from the University of Malaya, Kuala Lumpur, Malaysia, in 2009; and his Ph.D. degree in Electrical Engineering under the auspices of a dual Ph.D. program between the University of Malaya and Liverpool John Moores University, Liverpool, ENG, UK, in 2013. Since 2013, he has been with UM Power Energy Dedicated Advanced Centre (UMPEDAC), University of Malaya, where he is presently serving as a Senior Lecturer. Dr. Che has been an Associate Editor of the IET Electric Power Applications Journal and Alexandria Engineering Journal. He received a 2009 Kuok Foundation Postgraduate Scholarship Award for his Ph.D. studies, and a Frontier Researcher Award in 2016 from the Malaysian Ministry of Higher Education for his research work. His current research interests include multiphase machines and drives, fault-tolerant control, and power electronics converters for renewable energy applications.

Tan Kheng Suan Freddy received his BEng degree in Electrical Engineering from the Multimedia University, Malaysia, in 2010; and his Ph.D. degree from the University of Malaya, Kuala Lumpur, Malaysia, in 2015. He is presently serving as a Lecturer in the Asia Pacific University of Technology and Innovation (APU), Kuala Lumpur, Malaysia. Prior to working at APU, he was a Postdoctoral Research Fellow in the UM Power Energy Dedicated Advanced Centre (UMPEDAC), University of Malaya. Dr. Freddy was a recipient of an ASEAN-Korea Exchange Fellowship Award. He was a Visiting Research Scholar in the Power Electronics Laboratory, Ajou University, South Korea. His current research interests include power electronics converters, renewable energy and smart grids.

Ahmad Elkhateb is a Lecturer in power electronics with the School of Electronics, Electrical Engineering and Computer Science, Queen's University, Belfast, UK. His main research interests include power electronics, dc/dc converters, power generation, and grid integration. Dr Elkhateb is a Fellow of the Higher Education Academy, UK, Member of the EPSRC Associate Review College and Associate Editor for the IEEE Access, and the IET Power Electronics. 